science; encouraging co-operation between workers in different fields of mental science by arranging conferences; supporting specific lines of investigation by providing technical assistance, expenses or equipment for research workers; and arranging for the exchange of information with workers in other countries by financing attendance at regional and international meetings.

To further these objectives, the Fund proceeded to collect money and make grants on an increasing scale. It was fortunate in receiving grants from the Ford Foundation, the Leverhulme Trust, the Peel Trust and the National Society for Mentally Handicapped Children, as well as valuable support from the general public.
The Fund has now well-established procedures for inviting and assessing applications for support. Every research centre in Great Britain has been informed of the Fund's interest, of the kinds of help it is able to offer, and receives annually its invitation to prospective applicants.

During 1957 the Fund planned and issued invitations to the international conference recently held in Oxford. The theme of this conference was the concept of stress; its main object was to elucidate the variations of this concept as used in psychiatry and to relate them to each other and to the somewhat different concepts of stress which are used in physiology. Information about the Fund may be obtained from 39 Queen Anne Street, London, W.1.

\title{
GLACIOLOGICAL OBSERVATIONS ON RUWENZORI
}

\begin{abstract}
THE Department of Geography of Makerere College in the University College of East Africa has recently distributed a duplicated report* of eighteen quarto pages on the reconnaissance expedition to Mt. Ruwenzori conducted by four members of the College staff during December 28, 1957-January 12, 1958, under the leadership of Mr. F. P. Henderson, lecturer in geology. The object of the expedition was glaciological : it was hoped to make observations on some of the thirty odd glaciers of the mountain which would provide information as to their state during the International Geophysical Year. Oriented photographs were taken from marked sites of the highest peaks, Stanley Ice Plateau, and four or five of the principal glaciers; comparison with photographs taken by earlier expeditions reveals a general and considerable wastage of the Ruwenzori glaciers. In addition, a hut was erected above the snow line, a survey base was marked and measured, and from it the positions of a series of markers on the Elena glacier determined. Only one of several markers placed on this glacier by previous expeditions was discovered, and even this was useless since its original position could not be fixed.

It is concluded by the loader that relatively small expeditions of this type at fairly frequent intervals * Report of the Makerere College Ruwenzori Reconnaissance December 1957 to January 1958. Pp. 18. (Kampala: Geography
Department, Makerere College, 1958.)
\end{abstract}

offer a more promising mode of attack on the problems of this mountain than do more elaborate expeditions widely spaced in time. Accordingly, it was planned to follow up the reconnaissance with a further expedition six months later. On June 23, The Times reported that this expedition, again under the leadership of Mr. Henderson, began the ascent of the mountain on June 10, but operations had to be given up on June 18 owing to the illness and death from pneumonia of Mr. William Dickins, lecturer in geography in the Department of Education. During the reconnaissance, one member of the expedition, Dr. Whittow, contracted bronchial trouble and retired from the mountain, and, indeed, high-altitude pneumonia is a well-known phenomenon on Ruwenzori.

The courage of the young men of these two expeditions in planning fairly regularly repeated observations on a mountain with such a notorious weather record and under conditions that allow of little time for acclimatization is wholly to be admired; but the tragic outcome of the second expedition leads one to express the hope that in future their plans may receive, in Government and university circles in Uganda, financial support sufficient to allow them to operate with larger margins and to permit the inclusion of a medically qualified member in the team.

Davio L. Lintox

\section{ROLE OF TURBULENT SCATTERING IN LONG-DISTANCE RADIO PROPAGATION AT METRE WAVE-LENGTHS}

\author{
By F. A. KITCHEN and DR. M. A. JOHNSON \\ Royal Naval Scientific Service, London
}

\begin{abstract}
COME controversy has recently arisen ${ }^{x}$ in regard $\checkmark$ to the practical confirmation of the theoretical prediction ${ }^{2,3}$ that a permanent mechanism of longdistance propagation of short radio waves will arise from scattering by randomly distributed irregularities of refractive index associated with atmospheric turbulence. Some recent experimental results which appear to confirm its presence at metre wave-lengths are now presented.
\end{abstract}

Following the series of metre-wave experiments recently described 4 , further work was carried out by the Admiralty Signal and Radar Establishment in November and December 1957, in the English Channel area, using a ship-borne transmitter against a shorebased receiver near Portsmouth, on a frequency of $203.5 \mathrm{Mc} / \mathrm{s}$. The transmitter and receiver were those used in previous experiments ${ }^{4}$, but with the addition of a high-speed continuous recorder of received field- 